\title{
Errors in nonword repetition: bridging short- and long-term memory
}

F.H. Santos ${ }^{1}$,

O.F.A. Bueno ${ }^{2}$ and S.E. Gathercole ${ }^{3}$

\section{Correspondence}

F.H. Santos

Departamento de Psicologia

Experimental, UNESP

Av. Dom Antônio, 2100

19806-173 Assis, SP

Brasil

Fax: +55-18-3302-5804

E-mail: flaviahs@assis.unesp.br

Part of a Doctoral thesis presented by F.H. Santos to the Department of Psychology, University of Durham, England, UK.

Research supported by FAPESP (No. 99/11989-4), AFIP and CAPES.

.....................

Received March 10, 2005 Accepted November 18, 2005 ..................

\author{
${ }^{1}$ Departamento de Psicologia Experimental, Universidade Estadual Paulista, \\ Assis, SP, Brasil \\ ${ }^{2}$ Departamento de Psicobiologia, Universidade Federal de São Paulo, \\ São Paulo, SP, Brasil \\ ${ }^{3}$ Department of Psychology, University of Durham, England, UK
}

\begin{abstract}
According to the working memory model, the phonological loop is the component of working memory specialized in processing and manipulating limited amounts of speech-based information. The Children's Test of Nonword Repetition (CNRep) is a suitable measure of phonological short-term memory for English-speaking children, which was validated by the Brazilian Children's Test of Pseudoword Repetition (BCPR) as a Portuguese-language version. The objectives of the present study were: i) to investigate developmental aspects of the phonological memory processing by error analysis in the nonword repetition task, and ii) to examine phoneme (substitution, omission and addition) and order (migration) errors made in the BCPR by 180 normal Brazilian children of both sexes aged 4-10, from preschool to 4 th grade. The dominant error was substitution $[\mathrm{F}(3,525)=180.47 ; \mathrm{P}$ $<0.0001]$. The performance was age-related $[\mathrm{F}(4,175)=14.53 ; \mathrm{P}<$ 0.0001]. The length effect, i.e., more errors in long than in short items, was observed $[\mathrm{F}(3,519)=108.36 ; \mathrm{P}<0.0001]$. In 5-syllable pseudowords, errors occurred mainly in the middle of the stimuli, before the syllabic stress $[\mathrm{F}(4,16)=6.03 ; \mathrm{P}=0.003]$; substitutions appeared more at the end of the stimuli, after the stress $[\mathrm{F}(12,48)=2.27 ; \mathrm{P}=$ 0.02]. In conclusion, the BCPR error analysis supports the idea that phonological loop capacity is relatively constant during development, although school learning increases the efficiency of this system. Moreover, there are indications that long-term memory contributes to holding memory trace. The findings were discussed in terms of distinctiveness, clustering and redintegration hypotheses.
\end{abstract}

Key words - Children

- Working memory

- Phonological memory

- Nonword repetition

- Language acquisition

- Phonological loop

\section{Introduction}

According to Baddeley and Hitch's model (1), the phonological loop is the component of working memory specialized in processing and manipulating limited amounts of speech-based information. Working memory contains a phonological store retaining speech-based information and a rehearsal or articulatory loop that serves to maintain decaying representations in the phonological store. The phonological memory is thought to play an important role in language skills during the early years, for instance: in learning to read, in comprehension of spoken language, and in vocabulary acquisition $(2,3)$. The main function of this component is to provide temporary storage of the unfamiliar 
sound structures of new words (vocabulary acquisition) from which more stable lexical representations are gradually constructed (3).

There is evidence that nonword (also called pseudoword) repetition is constrained by the phonological memory (2). A pseudoword consists of a stimulus within the structural rules of a natural language, i.e., it can be read, written and repeated but has no conceptual meaning or semantic value in the current lexicon of that language (4).

Pseudoword repetition skill is influenced by the phonotactics, i.e., the rules which govern the arrangements of allowable speech sounds within a given language (5). Phonotactic factors such as the presence of singleton consonants (6), wordlikeness (4,7-9), lexical syllable stress (10), and the presence of attested phoneme sequences (5) provide more accuracy in pseudoword repetition. For a review of probabilistic phonotactic influences on lexical development, see Coady and Aslin (5). Therefore, when a pseudoword contains phoneme combinations, which are high rather than low in frequency in the language (long-term memory knowledge), they enhance phonological memory performance (e.g., 7,9).

In 1994, Gathercole et al. (11) developed the Children's Test of Nonword Repetition (CNRep) which consists of 40 pseudowords containing 2, 3, 4, and 5 syllables (10 of each). The child hears a stimulus (e.g., "woogalamic") and has to repeat it immediately. The CNRep was considered to be a phonological short-term memory task because the phonological forms of the stimuli are unfamiliar and so require children to code new phonological sequences and maintain them in phonological memory without degradation for a short time until speaking them (9). The CNRep has been applied to normal children (e.g., 11) and Down syndrome children (12). Indeed, it has been an excellent marker for phonological short-term memory deficits $(11,13)$, and for the pheno- type of heritable forms of developmental specific language impairment in children (e.g., 14).

Nonword repetition has been a tool to investigate controversial issues of the working memory model related to the phonological loop role. For instance, Baddeley and colleagues $(3,6,7)$ stated that vocabulary acquisition is dependent on phonological memory (memory theory) while researchers such as Snowling et al. (8) pointed out that lexical knowledge has a causal effect on the development of phonological memory (linguist theory).

Error analysis of tasks such as serial recall and nonword repetition can help to understand how the stimuli are encoded in the phonological memory (15) and also provide information about the cognitive process involved in new word learning (16). Consequently it provides knowledge about both linguist and memory theories. Phonemic errors (when the identity of the target item is not present in any position in the repetition) are classified as substitution, omission and addition, while order errors (movement of the target to a non-target position in the output attempt) are classified as migration. For examples of phoneme and order errors in the present context see Appendix 1.

The syllable is composed of units, while the initial consonant is called onset, the vowel plus the final consonant is named rhyme; for instance, in a consonant-vowel-consonant structure such as mic, "m" is the onset and "ic" is the rhyme. Considering this linguistic aspect, error analysis indicated that nonwords are remembered in terms of smaller phonological units by both kindergartners (15) and adults (17). Brady et al. (18) found similar results showing that the onset of one syllable appears recombined with the vowel from another syllable. Thus, spoken syllables are codified in terms of onset and rhyme units and the use of linguistic structure for memory purposes does not depend on a high level of literacy or cognitive skill. 
The kinds of errors were highlighted in the CNRep normative data. Gathercole et al. (11) found predominance of the simple substitution error occasionally associated with omissions or with multiple omissions or substitutions in normal children aged 4-9 years. Other accounted errors were less than $1 \%$ of incorrect repetitions.

Pseudoword repetition tasks can be used to examine children's sensitivity to phonotactic structure within the lexicon. For instance, Coady and Aslin (5) demonstrated that young children are sensitive to the probabilistic phonotactic structure of their input language. Children aged 30 months repeated more accurately a high-phonotactic probability stimulus than a low-phonotactic probability stimulus, independently of the articulation effects and syllabic lexicon status. These children showed more repetition accuracy for the frequency of individual segments than for combinations of segments, in contrast to older children (40 months old). The authors concluded that sensitivity to all aspects of the sound structure increases with age and that during development the child incorporates acoustic-phonetic detail into the lexical entries.

In a further study, Gathercole et al. (16) assessed serial recall of monosyllabic words and nonwords of high, low and very low probability in 7- and 8-year-old children. Words were better recorded than nonwords. In fact, a recall advantage was observed for nonwords with high rather than low frequency in English. The authors argued that both lexicality and language phonotactic properties (long-term knowledge) contributed to storage and to the retrieval process in phonological short-term memory. According to the redintegration process, permanent memory representations are used to repair incomplete or fuzzy temporary memory traces $(16,19)$. But the redintegration process cannot operate when the trace is completely lost (16). Possibly differential levels of activation in the short-term memory store mediate it, as well as the reconstruction process of memory traces that have become degraded (19).

Other investigations have shown the influence of other factors on recall, for instance syllabic stress (20). Roy and Chiat (21) found a prosody structure effect whereby whole syllable errors were almost exclusively made with unstressed syllables, with those preceding stress being most vulnerable.

The Brazilian Children's Test of Pseudoword Repetition (BCPR), a Portuguese language version of the CNRep, has been developed, since word patterns in Portuguese differ from those in the English language in terms of stress and the numbers of syllables. BCPR respects the Portuguese phonotactic rules typical of words spoken during childhood. The test was validated (4) by testing 182 children aged 4-10 years from preschool to 4th grade, enrolled in government schools from rural and urban areas in different States of Brazil. No group or gender effects were observed. Age and Schooling effects were found, with younger children with less schooling obtaining lower scores on the test. As expected, a pseudoword length effect was observed, with repetition accuracy declining as a function of the number of syllables. A comparison with Digit Span was carried out, showing a high correlation between BCPR and Digit Span forward $(r=$ $0.50)$ and backward $(r=0.43)$. Partial correlation indicated that higher BCPR scores were associated with higher Digit Span. Indeed, while BCPR depended more on schooling, Digit Span was more related to development. For more details, see Santos and Bueno (4). Given that preschoolers and 1st-grade children were impaired in relation to other grades, the results fit well the assumption of Petersson et al. (22) that sub-lexical phonological processing and awareness of sublexical phonological structure are not acquired spontaneously but are modulated by the acquisition of orthographic knowledge. 
However, error analyses were not carried out. It would be relevant to determine if the Portuguese and English languages have similar patterns of errors since they differ in phonotactic rules, speed of articulation, etc. Indeed, it can be useful to understand more about the process underlying encoding across different ages.

The general objective of the present study was to investigate developmental aspects of the phonological memory processing by error analysis in the nonword repetition task. The specific objectives of the present study were: to systematize the error analysis in BCPR of Portuguese speakers aged 4 to 10 years. It would be helpful to understand what factors - such as schooling, age, pseudoword length, and constitution of the word, etc. - contribute to the development of phonological memory and to classify the phonemic (inclusion, substitution, exclusion) and order (migration) errors made by these children in the BCPR. This would explain how children encode the words they hear in the phonological memory, and the influence of long-term memory on this process.

\section{Material and Methods}

Prior to testing, informed written consent was obtained from the parents of the children. It was explained to each child that the experiment could be discontinued at any time. The Ethics Committee of the Universidade Federal de São Paulo approved the study.

\section{Participants}

The participants were recruited from government schools and divided into three groups: rural from the State of Minas Gerais $(\mathrm{N}=42)$, urban from the State of Minas Gerais $(N=41)$, urban from the State of São Paulo ( $\mathrm{N}=43)$, and preschool children from the State São Paulo $(\mathrm{N}=54)$. The inclusion criteria were normal intellectual level as de- termined with the Raven-Colored Matrices or the Stanford-Binet Intelligence Scale Revised and the absence of complaints from teachers and/or family about behavior and/ or learning difficulties. Since statistical analysis by ANOVA $[\mathrm{F}(2,121)=1.88 ; \mathrm{P}=0.15]$ did not indicate differences between the three groups (4), subjects were divided into groups by schooling: preschool $(\mathrm{N}=54)$ and $1 \mathrm{st}(\mathrm{N}$ $=23), 2$ nd $(\mathrm{N}=36), 3 \mathrm{rd}(\mathrm{N}=31)$, and 4 th $(\mathrm{N}$ $=36)$ grades. Scores on the BCPR by age and school grade were obtained in a previous study (4). The scores by schooling are presented here in Table 1.

In the present study, we analyzed the protocols of 180 children with BCPR responses ( 2 missed), 92 boys and 88 girls assessed by the BCPR.

\section{Procedure}

The children were assessed with a large battery of neuropsychological tests, which will not be included in this report. Children were always tested individually. The tests were administered in a single session and in randomized order.

The BCPR was applied to the subjects by live-voice presentation (4). Incorrect responses were noted on the answer sheet by the experimenter. The phonetic transcription was done for all 40 stimuli in each child's protocol. An error was classified as a substitution error when it involved a phoneme that was not the target phoneme for that position and could not be classified as a migration; in other words, a substitution error had to involve a phoneme that was not part of the original nonword. An omission error was scored when no phoneme appeared in the target position, an addition error when a new phoneme was included in any position of the nonword, and a migration error when the target phoneme occurred in an unexpected position (11). Each phoneme was scored as correct (1), substitution (S), omission $(\mathrm{O})$, addition $(\mathrm{A})$, or migration $(\mathrm{M})$ 
according to the target in the specific phoneme position (see examples in Appendix 1).

In order to carry out the error analyses of the BCPR, the incorrect responses of each nonword noted on the answer sheet were divided according to their phonotactic structure, i.e., type of consonant-vowel (cv) combination and pseudoword length - from 2 to 5 syllables. This allowed a precise identification of the phoneme in which the error occurred. For example, for the pseudoword "novelitiva" the phonotactic structure is $\mathrm{c} 1 \mathrm{v} 1-\mathrm{c} 2 \mathrm{v} 2-\mathrm{c} 3 \mathrm{v} 3-\mathrm{c} 4 \mathrm{v} 4-\mathrm{c} 5 \mathrm{v} 5$ and the length is 5 syllables; thus, if the child says novelitida there is substitution in the c5 position (for more examples, see Appendix 1). Analyses were carried out considering both of these factors. Next, 22 stimuli from the 40 nonwords with the same phonotactic structure of the cv type received a specific statistical treatment.

\section{Statistical analysis}

Three sets of analyses were performed. The first analysis included the 40 nonwords to characterize the sample errors and to account for the general errors of the participants. ANOVA was carried out for the BCPR data. The between-subject factors were age and schooling, while the within-subject factors were length and errors.

In the second set of analyses, the nonword error analysis was centered on stimuli with cv structure. For this purpose 22 pseudowords from the BCPR were selected (see Appendix 2). These stimuli were clustered according to the pseudoword length: 6 items of 2 syllables, 6 items of 3 syllables, 5 items of 4 syllables, and 5 items of 5 syllables. Error frequencies were calculated for kind of error and kinds of phoneme. The ANOVA within-subject factors were: lengths, errors and phonemes. Later, separate ANOVA tests for each kind of phoneme were carried out taking into account the within-subject factors: position and error separately for each length.

The third set of analyses considered errors in nonwords with cv structure according to the units. The same 22 stimuli from the second set were used. Individual phonemes were not analyzed but the units formed by the junction of consonants and vowels that constitutes each syllable of the nonword were considered. The word "unit" was preferred over "syllable" since in that context syllable represents the length of the stimulus, while unit represents the fragment of each stimulus independently of the pseudoword length. ANOVA was carried out for length, errors and units.

The Tukey post hoc test was used, with a significant alpha level of $\mathrm{P} \leq 0.05$.

\section{Results}

\section{General error analysis per subject}

For the first set of analyses the total number of phoneme errors was calculated for each subject considering each kind of error and the number of syllables of the stimuli. Table 1 shows the means and standard deviations for each kind of error for each school grade.

Schooling effect. A three-way ANOVA for repeated measures was carried out, with school grade being the between-subject factor (5), and error and pseudoword length being the within-subject factors (4). A significant Schooling effect was found: $[\mathrm{F}(4,175)=14.53 ; \mathrm{P}<0.0001]$, with preschool and 1st-grade students producing more errors than 2nd-, 3rd-, and 4th-grade students $(\mathrm{P}<0.05)$. A significant difference between kinds of error was found $[\mathrm{F}(3,525)$ $=180.47 ; \mathrm{P}<0.0001]$. Post hoc analysis of the data revealed that children produced more substitutions than other errors. Also, children produced more omissions than additions and migrations $(\mathrm{P}<0.05$ in both cases $)$. Regarding to Length effect $[F(3,525)=95.00$; $\mathrm{P}<0.0001]$, children produced more errors 
for 5-syllable stimuli than for 2-, 3-, and 4syllable ones. The number of errors for $4-$ syllable nonwords was higher than for 2and 3-syllable ones $(\mathrm{P}<0.05$ for both comparisons). A significant interaction between Schooling and Error effects was found $[\mathrm{F}(12,525)=9.69 ; \mathrm{P}<0.0001]$, with 4thgrade children making fewer errors than preschoolers and 1st-, 2nd-, and 3rd-grade students; besides, 4th-grade children produced less omission than preschoolers. The number of additions and migrations did not vary across school grades. The interaction between Schooling and Length effects was significant $[\mathrm{F}(12,525)=9.34 ; \mathrm{P}<0.0001]$. Preschoolers and 1st-grade children made more errors in 5-syllable than in 2-, 3-, and 4 -syllable nonwords $(\mathrm{P}<0.0004)$. Also, 2ndgrade children produced more errors in 5syllable than in 2- and 3-syllable stimuli $(\mathrm{P}=$ 0.0009). Another interaction observed was between Error and Length effects $[\mathrm{F}(9,1575)$ $=13.49 ; \mathrm{P}<0.0001]$. Substitution and omission were more frequent in 5-syllable nonwords than in 2-, 3-, and 4-syllable ones $(\mathrm{P}<$ $0.0002)$. Indeed, less addition and migration was observed in 2- and 3-syllable than in 5syllable stimuli $(\mathrm{P}<0.008$ and $\mathrm{P}<0.004$,
Figure 1. Schooling effect on errors. SUB = substitution; $\mathrm{OMI}=$ omission; $A D D=$ addition; $M I G$ = migration SYL $=$ syllable.
Table 1. Error frequency according to schooling and BCPR score.

\begin{tabular}{lccccc}
\hline & $\begin{array}{c}\text { Pre-school } \\
(\mathrm{N}=54)\end{array}$ & $\begin{array}{c}\text { 1st grade } \\
(\mathrm{N}=23)\end{array}$ & $\begin{array}{c}\text { 2nd grade } \\
(\mathrm{N}=36)\end{array}$ & $\begin{array}{c}\text { 3rd grade } \\
(\mathrm{N}=31)\end{array}$ & $\begin{array}{c}\text { 4th grade } \\
(\mathrm{N}=36)\end{array}$ \\
\hline BCPR $^{\mathrm{a}}$ & $30.8( \pm 5.1)$ & $31.9( \pm 4.1)$ & $34.4( \pm 3.6)$ & $34.5( \pm 3.8)$ & $36.7( \pm 2.6)$ \\
Substitution & $9.20( \pm 6.0)$ & $7.91( \pm 4.7)$ & $5.19( \pm 3.2)$ & $3.93( \pm 2.7)$ & $2.94( \pm 3.6)$ \\
Omission & $2.40( \pm 2.2)$ & $3.95( \pm 4.3)$ & $1.72( \pm 2.0)$ & $1.51( \pm 2.0)$ & $0.61( \pm 1.1)$ \\
Addition & $1.22( \pm 1.5)$ & $0.91( \pm 1.1)$ & $0.61( \pm 1.0)$ & $0.51( \pm 0.7)$ & $0.52( \pm 0.9)$ \\
Migration & $1.31( \pm 1.7)$ & $0.95( \pm 1.4)$ & $0.52( \pm 0.9)$ & $0.45( \pm 0.9)$ & $0.27( \pm 0.7)$
\end{tabular}

Data are reported as means $( \pm \mathrm{SD})$ for $\mathrm{N}=180$.

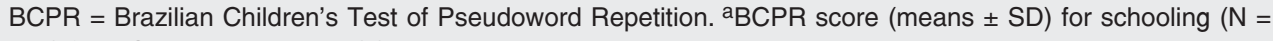
182) from Santos and Bueno (4).
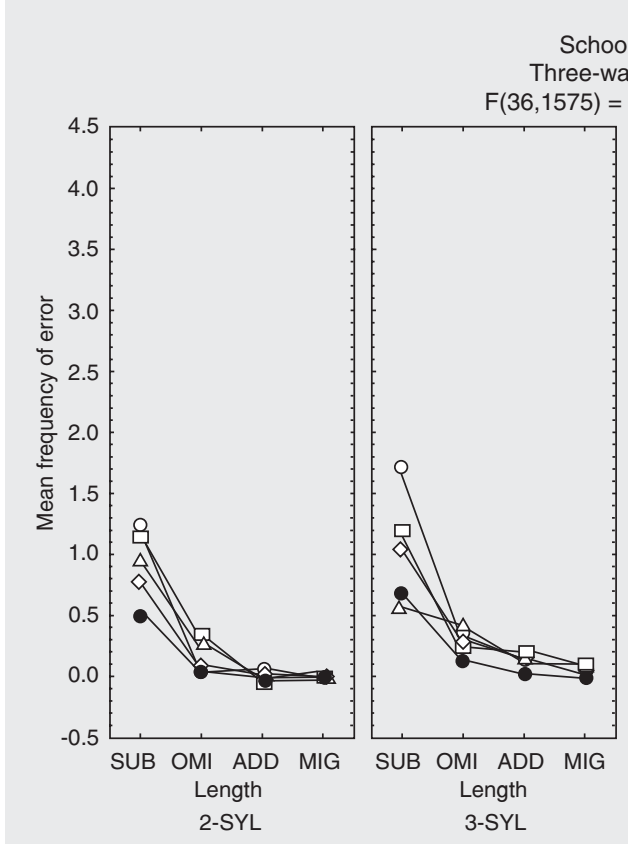

hooling effect $2.03 ; P<0.0003$
interaction
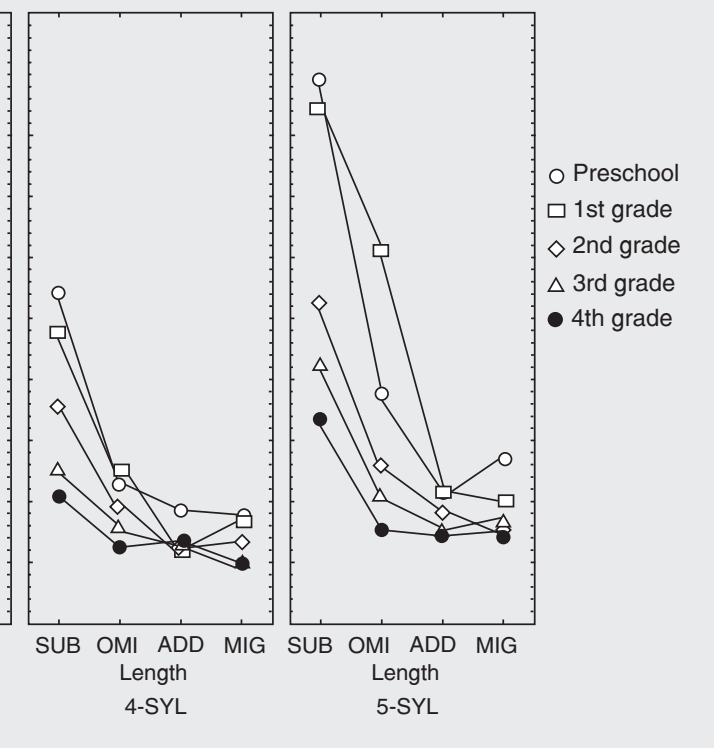
respectively). The significant interaction between Schooling, Error and Length effects $[\mathrm{F}(36,1575)=2.03 ; \mathrm{P}=0.0003]$ is illustrated in Figure 1.

Age effect. A three-way ANOVA for repeated measures was carried out. Age was the between-subject factor (7) and error (4) and pseudoword length were within-subject factors (4). An Age effect was detected $[\mathrm{F}(6,173)=9.09 ; \mathrm{P}<0.0001]$. Post hoc analysis of the data indicated that children aged 4 to 7 years made more errors than 10 year-old children and also that more errors were produced at ages 4,5 , and 7 than at age 9 ( $\mathrm{P}<0.0005)$. Significant differences between kinds of errors were found $[\mathrm{F}(3,519)$ $=230.42 ; \mathrm{P}<0.0001]$, with children producing more substitutions than other errors. Indeed, children produced more omissions than additions and migrations. A significant main effect of Length was established $[\mathrm{F}(3,519)=$ 108.36; $\mathrm{P}<0.0001$ ], with children producing more errors in 5-syllable nonword stimuli than in 2-, 3- and 4-syllable ones. The number of errors in 4-syllable stimuli was higher than in 2- and 3-syllable nonwords. There was a significant interaction between Age and Error effects $[\mathrm{F}(18,519)=6.55 ; \mathrm{P}<$
0.0001], with the number of substitutions being the same for children between 4 and 7 years of age, but being higher than other kinds of errors. Children aged 8 to 10 years made fewer substitution errors than younger children $(\mathrm{P}<0.0002)$. The number of omissions, migrations and additions was constant in the different age groups. Another significant interaction was between Age and Length effects $[\mathrm{F}(12,525)=9.34 ; \mathrm{P}<0.0001]$, with 4- and 8-year-old children making fewer errors in 5-syllable nonwords than in 2- and 3 -syllable nonwords $(\mathrm{P}<0.0005)$. At ages 5 to 7 , children made more errors in 5-syllable nonwords than in 2-, 3-, and 4-syllable ones $(\mathrm{P}<0.0008)$. At ages 9 and 10 , lengthrelated differences were not observed across kinds of errors. Indeed, an interaction between Error and Length effects was present $[\mathrm{F}(18,519)=4.94 ; \mathrm{P}<0.0001]$. The number of substitutions and omissions in 5-syllable nonwords was smaller than in 2- to 4-syllables ones $(\mathrm{P}<0.0005)$. Also, the number of migrations and additions in 5-syllable stimuli was lower than in 2- and 3-syllable ones. Figure 2 shows the 3-way interaction between Age, Error and Length effects $[\mathrm{F}(54,1557)=1.35 ; \mathrm{P}=0.049]$.
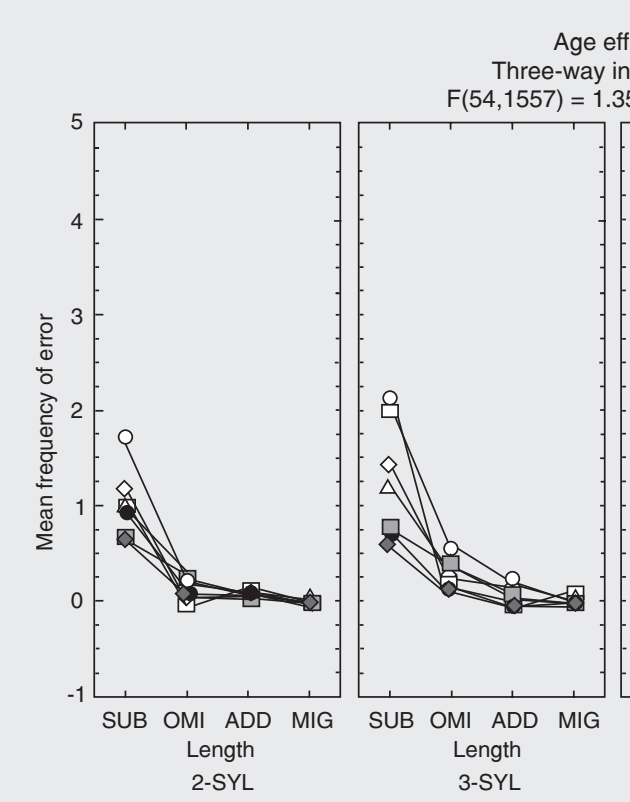

Age effect

Three-way interaction

.35; $\mathrm{P}<0.0496$

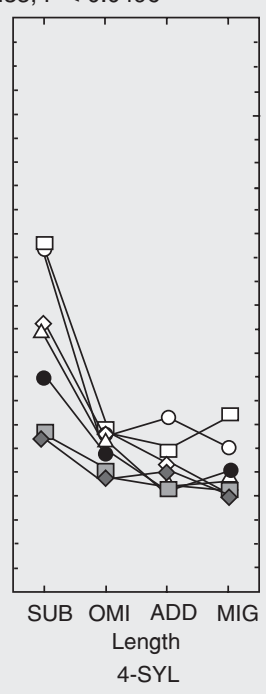

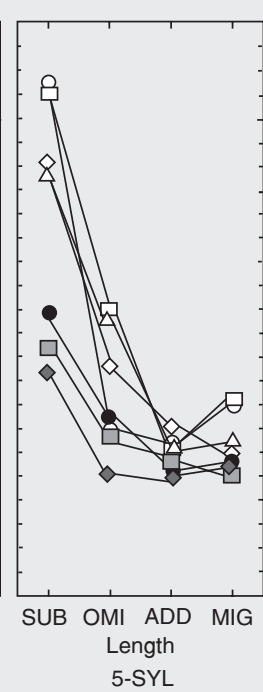

Figure 2. Age effect on errors. SUB $=$ substitution; $\mathrm{OMI}=$ omis sion; $\mathrm{ADD}=$ addition; $\mathrm{MIG}=\mathrm{mi}-$ gration; $S Y L=$ syllable. 
Analysis of consonant-vowel structure error by phonemes

For the second set of analyses, 22 nonwords of the 40 BCPR stimuli with the same phonotactic structure (cv) were selected (see Appendix 2) and clustered according to the pseudoword length. Frequencies of each kind of error and kind of phonemes were calculated for each stimulus.

\section{Overall phoneme effects}

A three-way ANOVA, 4 (pseudoword length) x 2 (phonemes; consonants $v s$ vowels) $\mathrm{x} 4$ (errors) was performed to investigate the overall effects. The Length effect was significant $[\mathrm{F}(3,18)=10.80 ; \mathrm{P}=0.0002]$, with more errors being observed in 5-syllable stimuli than in 2-, 3-, and 4-syllable pseudowords. A Phoneme effect was present $[\mathrm{F}(1,18)=68.74 ; \mathrm{P}<0.0001]$, with the errors occurring dominantly in consonants rather than in vowels. An Error effect was found $[F(3,54)=65.09 ; \mathrm{P}<0.0001]$, with substitution being the most frequent kind of error. A significant interaction between Length and Phoneme effects $[\mathrm{F}(3,18)=9.61$; $\mathrm{P}=0.0005]$ revealed more errors in 5-syllable consonants than in all phonemes and lengths. In point of fact, children made fewer errors in 3- and 4-syllable vowels when compared to 3- and 4-syllable consonants, respectively. An interaction between Length and Error effects was found $[\mathrm{F}(9,54)=4.59$; $\mathrm{P}=0.0001]$, with 5-syllable substitution being more frequent than all errors and syllables. Also, 5-syllable addition was more frequent than 2- and 3-syllable addition; besides, 2-, 3-, and 4-syllable migrations were less frequent than 2-, 3-, and 4-syllable substitutions, respectively. Interaction between Phoneme and Error effects was detected $[\mathrm{F}(3,54)=66.19 ; \mathrm{P}<0.0001]$, with consonant substitution being more frequent than all other errors in both kinds of phonemes; besides, vowel migration was less frequent than consonant omission. Finally, an interaction between the three factors was observed $[F(9,54)=6.46 ; P<0.0001]$, whereby 5 -syllable consonant substitution was more frequent than all lengths, kinds of errors and kinds of phonemes. Additionally, it confirmed previous interactions and also indicated that 2-, 3-, and 4-syllable consonant substitutions were higher than 2-, 3-, and 4syllable vowel substitutions, respectively.

\section{Consonants}

Analyses were performed separately for two phoneme categories, i.e., consonants and vowels, using the Tukey post hoc test for all comparisons.

A two-way ANOVA for 2-syllable stimuli comparing error (4) and 2-consonant position ( $\mathrm{c} 1$ and $\mathrm{c} 2$ ) revealed a significant main effect of Error $[F(3,15)=14.7 ; \mathrm{P}<0.0001]$, with substitution being the dominant kind of error $(\mathrm{P}<0.05)$. On the other hand, Position effect $[\mathrm{F}(1,5)=1.5 ; \mathrm{P}=0.27]$ and the remaining interaction $[\mathrm{F}(3,15)=0.70 ; \mathrm{P}=$ $0.56]$ were not significant.

An Error effect $[\mathrm{F}(3,15)=49.0 ; \mathrm{P}<$ 0.0001] was revealed by two-way ANOVA for 3-syllable nonwords considering the error factor (4) and the 3-consonant position (c1, c2, and c3). Substitution was the dominant kind of error. However, there was no significant difference in Position effect $[\mathrm{F}(2,10)=1.31 ; \mathrm{P}=0.31]$ or interaction between these two variables $[\mathrm{F}(6,30)=0.82$; $\mathrm{P}=0.55]$.

ANOVA further performed for 4-syllable stimuli comparing the error (4) and the 4consonant positions (c1, c2, c3, and c4) revealed a significant main effect of Error $[\mathrm{F}(3,12)=6.97 ; \mathrm{P}=0.005]$, with substitution being the dominant kind of error. Although a Position effect was not observed $[\mathrm{F}(2,10)=$ $1.31 ; \mathrm{P}=0.31]$, an interaction between Error and Position effects $[\mathrm{F}(9,36)=2.19 ; \mathrm{P}=$ 0.04 ] indicated that more errors occurred in the $\mathrm{c} 2$ and $\mathrm{c} 3$ positions for substitutions than 
for other errors $(\mathrm{P}<0.05)$.

For 5-syllable nonwords, a two-way ANOVA comparing the error (4) and 5consonant positions (c1, c2, c3, c4, and c5) indicated a significant Error effect $[\mathrm{F}(3,12)$ $=26.15 ; \mathrm{P}<0.0001]$ with substitution being the dominant kind of error. A Position effect was present $[F(4,16)=4.67 ; \mathrm{P}=0.01]$, with more errors occurring in the $\mathrm{c} 3$ position than in the $\mathrm{c} 1$ and $\mathrm{c} 2$ positions. The interaction between Error and Position effects $[\mathrm{F}(12,48)$ $=2.52 ; \mathrm{P}=0.04]$ revealed that more errors occurred in the $\mathrm{c} 5$ position for substitutions than in positions $\mathrm{c} 1$ and $\mathrm{c} 4$ for omissions, $\mathrm{c} 1$, $\mathrm{c} 2$, and $\mathrm{c} 3$ for additions, and $\mathrm{c} 1$ and $\mathrm{c} 5$ for migrations $(\mathrm{P}<0.05$ for all cases $)$.

\section{Vowels}

Significant differences between errors were found for 2-syllable stimuli comparing error (4) and 2-vowel position (v1 and v2), as revealed by two-way ANOVA $[\mathrm{F}(3,15)=$ $2.4 ; \mathrm{P}=0.10]$, but there was no interaction between these variables $[\mathrm{F}(3,15)=0.72 ; \mathrm{P}=$ $0.97]$ and no Position effect $[\mathrm{F}(1,5)=1.5 ; \mathrm{P}$ $=0.33$. .

A two-way ANOVA for 3-syllable nonwords considering the Error factor (4) and the 3-vowel position (v1, v2, and v3) revealed a significant main effect of Error $[\mathrm{F}(3,15)=49.0 ; \mathrm{P}<0.0001]$, with substitution being more frequent than migration $(\mathrm{P}<$ 0.05). Nevertheless, no Position effect $[\mathrm{F}(2,10)=2.96 ; \mathrm{P}=0.09]$ or interaction $[\mathrm{F}(6,30)=1.20 ; \mathrm{P}=0.33]$ was observed.

Regarding 4-syllable stimuli, when comparing the error (4) and the 4-vowel positions (v1, v2, v3, and v4) no differences between errors was revealed by two-way ANOVA $[\mathrm{F}(3,12)=3.15 ; \mathrm{P}=0.06]$. Also, no Position effect $[\mathrm{F}(3,12)=0.79 ; \mathrm{P}=0.52]$ or interaction was found.

Regarding the 5-syllable nonwords, when comparing the error (4) and 5-vowel position (v1, v2, v3, v4, and v5), a two-way ANOVA showed an Error effect $[\mathrm{F}(3,12)=$
$8.55 ; \mathrm{P}=0.002]$ with substitution and omission being more frequent than migration $(\mathrm{P}$ $<0.05)$. A Position effect was present $[\mathrm{F}(4,16)=5.95 ; \mathrm{P}=0.03]$, with more errors occurring at position $\mathrm{V} 3$ than at positions $\mathrm{V} 4$ and V5. However, there was a non-significant interaction between Error and Position effects $[\mathrm{F}(12,48)=0.92 ; \mathrm{P}=0.52]$.

\section{Consonant-vowel structure analysis by unit}

The same stimuli from the second set of analyses were considered in these analyses. However, not as individual phonemes but as units formed by consonants and vowels, i.e., the syllables that constitute each nonword.

A two-way ANOVA was carried out for 2-syllable stimuli comparing error (4) and 2 units (cv1v1 and c2v2). An Error effect was observed $[\mathrm{F}(3,15)=19.08 ; \mathrm{P}<0.0001]$, with substitution being the dominant error. Conversely, no Unit effect $[\mathrm{F}(1,5)=2.29 ; \mathrm{P}=$ $0.19]$ or interaction $[\mathrm{F}(3,15)=2.18 ; \mathrm{P}=$ $0.13]$ was observed.

An Error effect was found $[\mathrm{F}(3,15)=$ $37.68 ; \mathrm{P}<0.0001$ ] by two-way ANOVA for 3 -syllable nonwords considering the error factor (4) and the 3 units (c1v1, c2v2 and $\mathrm{c} 3 \mathrm{v} 3$ ), with substitution being more frequent than the other kinds of error $(\mathrm{P}<0.05)$. However, there were no statistically significant differences in terms of Units $[\mathrm{F}(2,10)=$ $2.02 ; \mathrm{P}=0.18]$, nor was there an interaction between Error and Unit effects $[\mathrm{F}(6,30)=$ $1.68 ; \mathrm{P}=0.15]$.

A two-way ANOVA was performed for 4-syllable stimuli comparing the error (4) and the 4 units (c1v1, c2v2, c3v3 and c4v4). An Error effect was observed $[\mathrm{F}(3,12)=$ $8.60 ; \mathrm{P}=0.02$ ], with more substitutions than other errors occurring. No Unit effect $[\mathrm{F}(3,12)$ $=1.29 ; \mathrm{P}=0.32]$ or interaction was detected $[\mathrm{F}(9,36)=1.89 ; \mathrm{P}=0.08]$.

ANOVA for 5-syllable nonwords comparing the error (4) and 5 units (c1v1, c2v2, $\mathrm{c} 3 \mathrm{v} 3, \mathrm{c} 4 \mathrm{v} 4$, and $\mathrm{c} 5 \mathrm{v} 5)$ revealed an Error effect $[\mathrm{F}(3,12)=36.23 ; \mathrm{P}<0.0001]$, with 
substitution being the dominant kind of error $(\mathrm{P}<0.05)$. A unit effect was present $[\mathrm{F}(4,16)$ $=6.03 ; \mathrm{P}=0.003]$, with more errors occurring in unit 3 than in units $1,2,4$, and 5 . There was a significant interaction $[\mathrm{F}(12,48)$ $=2.27 ; \mathrm{P}=0.02]$ which indicated more errors in unit 3 for substitution than for other errors and units. Indeed, substitution in unit 5 was more frequent than in unit 5 of additions and migrations (see Figure 3 - Unit effect two-way interaction).

Table 2 shows qualitative aspects related to the main effects observed in the present analysis.

\section{Discussion}

The present study analyzed phonemic (inclusion, substitution, exclusion) and order (migration) errors made by Brazilian children aged 4-10 years in the BCPR, a phonological working memory test. The analyses were carried out in three different ways. The first set of analyses were conducted to fulfill the first objective of this study, and a systematized analysis of the errors in the BCPR of Portuguese speakers aged 4-10 years is presented. The two subsequent analyses carried out according to kind
Figure 3. Unit effect for 5-syllable nonwords. SUB $=$ substitution; $\mathrm{OMI}=$ omission; $\mathrm{ADD}=\mathrm{ad}-$ dition; $\mathrm{MIG}=$ migration; $\mathrm{c}=$ consonant; $\mathrm{v}=$ vowel.

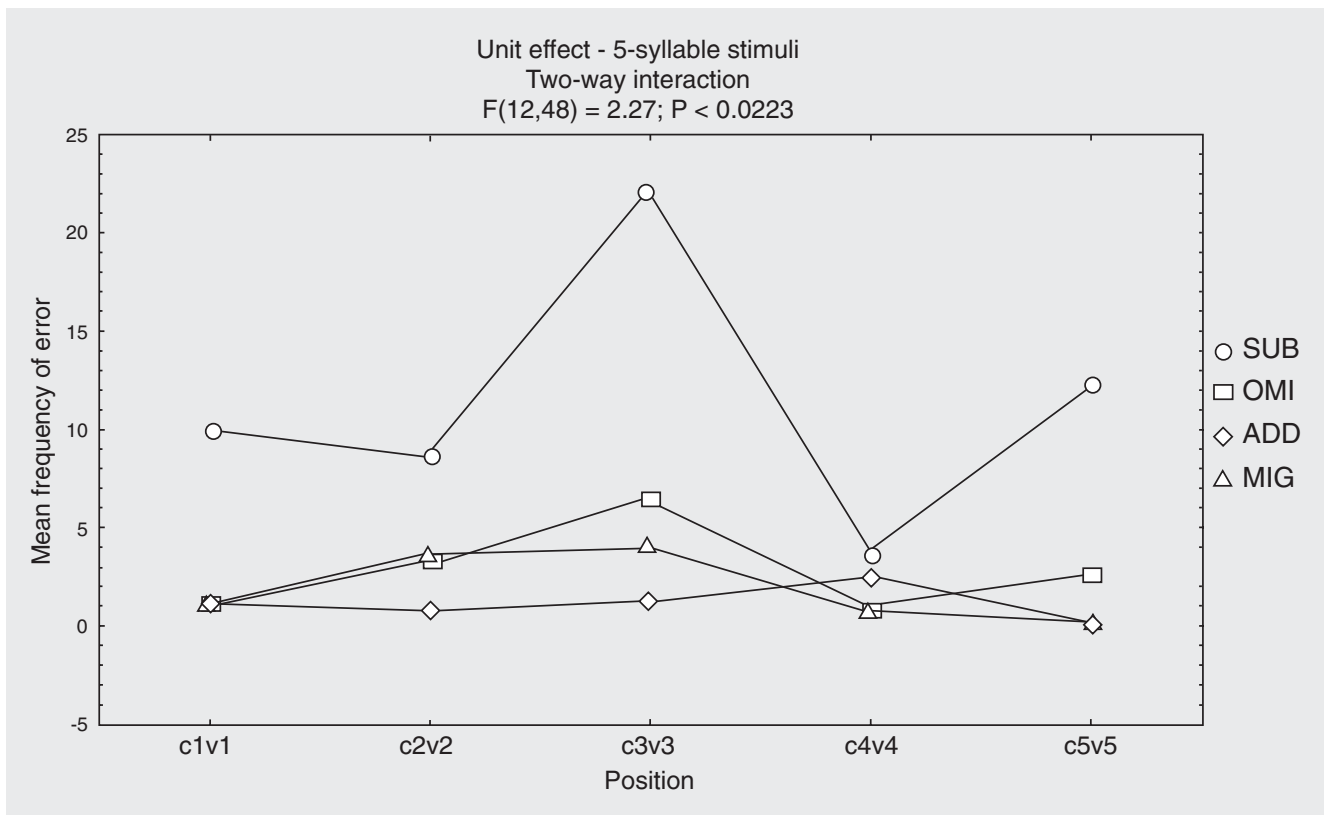

Table 2. Typical substitutions in 5-syllable consonant-vowel phonotactic structure.

\begin{tabular}{|c|c|c|c|c|c|c|}
\hline & C3 & V3 & Unit 3 & $\mathrm{C} 5$ & V5 & Unit 5 \\
\hline Belinidade & $d-\mathbf{m}-1$ & & & $\mathrm{~S}$ & & do \\
\hline Cabajucaba & $d-z-s$ & & ti - ci - pi - li - di & $d-\mathbf{v}-\mathbf{s}$ & 0 & \\
\hline Paripadura & $c-z-t-d-b-l h$ & & & L & & \\
\hline Melanitito & $\mathrm{I}-\mathbf{m}-\mathrm{vj}-\mathrm{t}-\mathrm{d}$ & $e-a$ & $\mathrm{Me}$ & $b-p-d-n-v$ & & $\mathrm{mi}$ \\
\hline Novelitiva & $\mathrm{v}$ & 0 & tis - ne & $b-n-m-d-t-r-f$ & e & \\
\hline
\end{tabular}

The more frequent phoneme substitutions are given in bold. $\mathrm{C} 3=$ third consonant of the nonword; $\mathrm{V} 3=$ third vowel of the nonword; Unit $3=$ the third syllable of the nonword; $\mathrm{C} 5=$ fifth consonant of the nonword; $\mathrm{V} 5=$ fifth vowel of the nonword; Unit $5=$ fifth syllable of the nonword. $\mathrm{cv}=$ consonant-vowel. 
of phonemes and unit, respectively, were done to fulfill the second objective of the present study, with errors on the BCPR being classified as phonemic (inclusion, substitution, exclusion) and as order errors (migration). Additionally, some qualitative aspects are commented upon.

\section{General error analysis by subject}

The error analysis confirmed some previous results obtained in BCPR score analysis (4). Thus, Age, Schooling and Length effects were found, indicating that this task is related to development, since the occurrence of errors decreased in older children. However, according to our previous report (4), when ANCOVA was calculated with Schooling as co-variant, the Age effect disappeared. In other words, BCPR scores change with age but are influenced by schooling. Therefore, schooling contributes to this improvement in performance since preschoolers and 1st graders produced more errors than 2nd, 3rd and 4th graders. It has been already demonstrated that phonological awareness is not completely established in illiterate subjects (22). Indeed, children made fewer errors in short pseudowords (2 and 3 syllables) than in long pseudowords (4 and 5 syllables), as if long stimuli reflected the limitation of capacity for phonological memory. Errors on the BCPR declined with increasing schooling and age, although the Length effect was evident across all ages. These results are consistent with changes in efficiency more than with capacity of phonological working memory $(4,23,24)$.

We repeated the CNRep finding that substitution error is the dominant one (12). Indeed, we found a higher frequency of omission errors than of addition and migration. This suggests that the nature of the errors is not influenced by phonotactic differences between languages but rather that there is a general language pattern, in addition to specific tongue features, as we will indicate in the subsequent sections.

\section{Analysis of consonant-vowel structure error by phoneme}

The present results confirm that vowels are the easiest to be discriminated while consonants are shorter and require more precise articulation (25). Consonant analysis indicated that short pseudowords do not reflect differences in consonant error position. In fact, there was no Position effect for 2to 4-syllable pseudowords, whereas an effect was observed for 5-syllable pseudowords, with errors predominantly occurring at consonant position 3 (e.g., belinidade/ belimidade). However, the interaction between position and kind of error indicated that more substitutions than migrations occurred at consonant position 5 (e.g., paripadura/paripadula). Substitutions at consonant position 5 were more frequent, for instance, than omissions, additions and migrations at consonant position 1 . This reflects a pattern since the trace vulnerability in this kind of error in Portuguese phonotactic items commonly occurs at the end of the stimuli.

In vowel analysis, an Error effect was evident only in 3- and 5-syllable pseudowords. In the first case, substitution was more frequent than migration; in the second, both substitution and omission were more frequent than migration. A Position effect was demonstrated only in 5-syllable pseudowords, where errors dominantly appeared at vowel position 3 (e.g., novelitiva/novelotiva) in comparison to vowel positions 4 and 5 . This is consistent with a study showing that these errors preceded the stressed syllable (21).

Thus, errors for both consonants and vowels of long pseudowords were frequent in the middle of the stimuli (c3v3). This pattern is not similar to the pattern observed in English speakers for nonword repetition and might be explained by other aspects. 
In the serial position curve generated by the free recall task, there was more retrieval in the first items (Primacy effect) and in the last items (Recency effect) rather than in the intermediate items (2). It is possible that a single word might reflect a similar pattern of the recall process seen in the serial position curve. For instance, the majority of errors (loss of information) in 5-syllable nonwords occurred dominantly in the middle of the stimuli.

On the other hand, substitution seems to behave in a different way. In the Portuguese language the typical stress pattern in long words is weak-weak-weak-strong-weak (e.g., felicidade/happiness). The syllabic stress in all 5-syllable nonwords from this study followed this rule. Apparently it did determine a dislocation of the substitution from the middle to the end of the pseudoword (c5v5) after the syllabic stress.

In the free recall task, the Recency effect is resistant to manipulation and is rarely decreased in the serial position curve. For instance, Baddeley (2) showed that a concurrent span task did not abolish the Recency effect in the free recall. On the other hand, if substitution at the end of the long pseudoword is similar to an extinction of the Recency effect, this suggests that syllabic stress overshadows the last syllable. It is possible that a clustering strategy of units was used, in which case, the syllabic stress unit (c4v4) would be a watershed between the first cluster (positions 1 to 3 ) and the second cluster (position 5 ). This last unit (c5v5) would be lost since the load exceeds the system capacity or because the distinctiveness of the syllabic stress would occupy the attention of the speaker, causing the loss of the memory trace of this unit.

According to Baddeley (2), the Recency effect is not always dependent on short-term storage, but can be mediated by semantic units or by retrieval strategy, in which case, items that represent extremes of a certain category receive more emphasis than inter- mediate items. Since in the present study children produced more substitutions than omissions (total loss of information), mainly in the last unit (c5v5), it is plausible to suppose that they were using this retrieval strategy. They noticed that there was a last unit but were unable to codify it in depth (26) due to the obscurity generated by syllabic stress. Indeed, substitution at the end of the stimuli generated typically familiar units, suggesting the use of lexical knowledge to compose the substitution (see examples in Table 2).

In 5-syllable nonwords children constructed frequent words by junction of the syllabic stress unit and substitution, i.e., positions 4 plus 5. For instance, the repetition of the nonword cabajucaba would be cabajucada ("cada" means each) or cabajucasa ("casa" means house). The same occurred for the nonword melanitipo ("tipo" means type) and in others. In some cases, the common termination of a word (e.g., ido or ida) was used as a substitution in the nonword with non-common termination, such as melanitito. However, when the nonword had a frequent termination (e.g., ade in belinidade) fewer errors occurred at that position. Further comments related to this approach will be made in the next section.

Analysis of consonant-vowel structure by unit

The phonemes were clustered into phonotactic syllables (consonant plus vowel) named here units from 1 to 5 - respecting phoneme order and stimulus length (number of syllables). This was done for each of the 22 pseudowords previously selected.

The results showed an Error effect for pseudowords of all lengths (from 2 to 5 syllables). Neither unit nor interaction effects were shown for 2- to 4-syllabe pseudowords, but a Unit effect was observed for 5syllable pseudowords. Error analysis by phoneme showed that more errors occurred in the middle of the stimuli - unit $3(\mathrm{c} 3 \mathrm{v} 3)$, i.e., 
before the syllabic stress (e.g., melanitito/ melamitito). In fact, substitution in unit 5 , after the syllabic stress, was dominant over additions and migrations at the same unit (e.g., melanitito/melanitimi). These results revealed that unit or phoneme analysis contributes in a similar manner to identifying the Position effect. However, phoneme analysis also showed that consonants are more affected than vowels, as expected according to previous studies (e.g., 24).

Studies have shown that both kindergartners (15) and adults (17) remember nonwords as small phonological units. The present study supported this assumption, with emphasis on the qualitative aspects presented in Table 2. Speech production depends on the place of articulation (place where the approximation occurs or the articulators meet) or on the way of articulation, i.e., the way the air chain passes through the supralaryngeal canals (27).

Considering the place of articulation, the following phonemic substitutions were the most frequent: " $b$ " for $\mathrm{v}$ (from bilabial to tipteeth), "v" for $\mathrm{f}$ (both lip-teeth), " $\mathrm{n}$ " for $\mathrm{m}$ (from alveolar to bilabial), " $\mathrm{j}$ " for $\mathrm{s}$ (from palatal to alveolar), "p" for t (bilabial to tipteeth), "t" for d (both tip-teeth), and "v" for $\mathrm{d}$ (lip-teeth to tip-teeth). This appeared in pseudowords of other lengths and at other consonant positions as well. However, the same items did not show a change in articulation: "v" for $\mathrm{f}$ (both fricative), " $\mathrm{n}$ " for $\mathrm{m}$ (both nasal), "j" for s (both fricative), "p" for t (both occlusive), " $t$ " for d (both occlusive). Phoneme exceptions were "b" for v (from occlusive to fricative) and " $v$ " for $d$ (from fricative to occlusive). Thus, the phoneme variability in the substitution error of Portuguese phonotactic items reflected more changes in the place of articulation than in the way of articulation.

Another interesting aspect is that in all cases of substitution in unit 3 of the nonword cabajucaba the phoneme /u/ was changed to the phoneme /i/. This is a common occur- rence in Portuguese long words having the phoneme / $\mathrm{i}$ / in the 3rd unit (e.g., autoridade/ authority, comerciante/merchant, catolicismo/ Catholicism, etc.). The same occurred for the stimulus novelitiva, in which the phoneme /i/ at position 3 was substituted by /o/ or /e/ such as in words like locomotiva/ locomotive, acelerado/accelerated. This would not be expected from a linguistic point of view since the vowel changes imply different lip movements: /i/ is open while /u/ is closed. These qualitative aspects, taken together, suggest that children try to regularize the speech based on familiar information; in other words, they search for some information available in their lexicon to help them with the reconstruction of the stimuli, in agreement with the redintegration hypothesis (28). According to Thorn et al. (19), items that regularly co-occur achieve higher temporary levels of activation in the shortterm memory store, leading to a lower level of complete item loss since they are regularly found in high frequency words.

The last consideration concerns audiometry. Participants' inclusion criteria were: absence of schooling difficulties related to learning or behavior and normal IQ. No child with a neurological or psychiatric diagnosis was admitted. Besides, all children were submitted to a battery of neuropsychological tests and none of them showed difficulty in understanding or performing auditory-verbal task, such as Digit Span (4). Even though audiometry was not carried out, all of these aspects, taken together, indicate that the sample had accurate auditory skills. It would be helpful to explain lip to lip-teeth shifts of consonant substitution that occurred in a few cases. However, in some situations children opted for a phoneme substitution that cannot be explained only by linguistic aspects such as place of articulation (for instance, vowel substitutions, such as $/ \mathrm{u} /$ for $/ \mathrm{i} /$ ). This does support the hypothesis presented here that substitution errors on the BCPR are associated with loss of 
memory trace of units of information.

We conclude that the analysis of error on the BCPR supports the idea that nonword codification is fragmented into small items $(15,17)$. The errors occur more in consonants than in vowels and are more frequent in younger children. In other words, preschool children do not yet have automatic segmentation of frequent words and for this reason are less efficient in processing nonfamiliar items. They are guided by syllabic combinations typical of the language as a strategy to increase item retention, i.e., by long-term memory. For instance, in the nonword cabajucaba, typical substitution occurred in the third unit (c3v3) like cabaticaba or cabacicaba. These words mimic Portuguese words such as Piracicaba (the name of a city in São Paulo State) or jabuticaba (a tropical fruit). This process is evident in long nonwords (5 syllables) for which phonological loop capacity is exceeded. The Length effect, whereby more errors were observed with long than short stimuli, was observed in children aged 4 to 8 years. The BCPR results suggest that phonological loop capacity is relatively constant during development, al- though school learning increases the efficiency of this system (4). In other words, the frequency of substitution at the end of the stimulus, after the syllabic stress, was higher than that of other kinds of errors. Two possibilities are to be considered. First, syllabic stress creates a distinction in the units to be remembered. It occupies the attention and prevents the maintenance of the trace of the last unit (overshadowing). Second, the units preceding the syllabic stress are clustered as unique information; another cluster may be formed after the syllabic stress, but the last unit would be lost because it exceeds the phonological loop capacity.

\section{Acknowledgments}

We especially thank the parents and children that participated in the study. We also thank Michael Ziessler (University of Newcastle, UK) and Gerda Arts (University of Durham, UK) for advice with the statistical analysis, Mike Davenport (University of Durham, UK) for converting the nonwords into the phonetic code, and Everild Hindley (UK) for revising the English text.

\section{References}

1. Baddeley AD \& Hitch GJ (1974). Working memory. In: Bower G (Editor), The Psychology of Learning and Motivation. Vol. 8. Academic Press, London, UK, 47-90.

2. Baddeley AD (1986). Working Memory. Oxford University Press, Oxford, UK.

3. Baddeley AD, Gathercole SE \& Papagno C (1998). The phonological loop as a language learning device. Psychological Review, 105: 158-173.

4. Santos FH \& Bueno OFA (2003). Validation of the Brazilian Children's Test of Pseudoword Repetition in Portuguese speakers aged 4-10 years. Brazilian Journal of Medical and Biological Research, 36: 1533-1547.

5. Coady JF \& Aslin RN (2004). Young children's sensitivity to probabilistic phonotactics in the developing lexicon. Journal of Experimental Child Psychology, 89: 183-213.

6. Gathercole SE \& Baddeley AD (1989). Evaluation of the role of phonological STM in the development of vocabulary in children. Journal of Memory and Language, 28: 200-213.

7. Gathercole SE, Willis CS, Baddeley AD et al. (1991). The influences of number of syllables and wordlikeness in children's repetition of nonwords. Applied Psycholinguistics, 12: 349-367.

8. Snowling M, Chiat S \& Hulme C (1991). Words, nonwords and phonological processes: Some comments on Gathercole, Willis, Emslie \& Baddeley. Applied Psycholinguistics, 12: 369-373.

9. Gathercole SE (1995). Is nonword repetition a test of phonological memory or long-term knowledge? It all depends on the nonwords. Memory Cognition, 23: 83-94.

10. Dollaghan C, Biber M \& Campbell T (1993). Constituent syllable effects in a nonsense-word repetition task. Journal of Speech and Hearing Research, 36: 1051-1054.

11. Gathercole SE, Willis CS, Baddeley AD et al. (1994). The children's test of nonword repetition: a test of phonological working memory. Memory, 2: 103-127.

12. Laws $\mathrm{G}$ (1998). The use of nonword repetition as a test of phonological memory in children with Down syndrome. Journal of Child Psychology and Psychiatry, 39: 1119-1130.

13. Gathercole SE (1998). The development of memory. Journal of Child Psychology and Psychiatry, 39: 3-27. 
14. Bishop DVM, North T \& Donlan C (1996). Nonword repetition as a behavioural marker for inherited language impairment: Evidence from a twin study. Journal of Child Psychology and Psychiatry, 37: 3-27.

15. Treiman R (1995). Errors in short-term memory for speech: a developmental study. Journal of Experimental Psychology: Learning Memory and Cognition, 21: 1197-1208.

16. Gathercole SE, Frankish CR, Pickering SJ et al. (1999). Phonotactic influences on short-term memory. Journal of Experimental Psychology: Learning Memory and Cognition, 25: 84-95.

17. Treiman R \& Danis C (1988). Short-term memory errors for spoken syllables are affected by the linguistic structure of the syllables. Journal of Experimental Psychology: Learning Memory and Cognition, 14: 145-152.

18. Brady S, Mann V \& Schmidt R (1987). Errors in short-term memory for good and poor readers. Memory and Cognition, 15: 444-453.

19. Thorn ASC, Gathercole SE \& Frankish CR (2005). Redintegration and the benefits of long-term knowledge in verbal short-term memory: an evaluation of Schweickert's (1993) multinomial processing tree model. Cognitive Psychology, 50: 133-158.

20. Frankish C (1995). Intonation and auditory grouping in serial recall. Applied Cognitive Psychology, 9: 5-22.

21. Roy P \& Chiat S (2004). A prosodically controlled word and nonword repetition task for 2- to 4-year-olds: evidence from typically developing children. Journal of Speech and Hearing Research, 47: 223-234.

22. Petersson KM, Reis A, Askelof S et al. (2000). Language processing modulated by literacy: a network analysis of verbal repetition in literate and illiterate subjects. Journal of Cognitive Neuroscience, 12: 364-382.

23. Case RD, Kurland M \& Goldberg J (1982). Operational efficiency and the growth of short-term memory span. Journal of Experimental Child Psychology, 33: 386-404.

24. Gathercole SE \& Baddeley AD (1993). Working Memory and Language. Lawrence Erlbaum Associates, Hove, England, UK.

25. Norrelgen F, Lacerda F \& Forssberg H (1999). Speech discrimination and phonological working memory in children with ADHD. Developmental Medicine and Child Neurology, 41: 335-339.

26. Craik FIM \& Lockhart RS (1972). Levels of processing: A framework for memory research. Journal of Verbal Learning and Verbal Behavior, 11: 671-684.

27. Maia EM (1991). No Reino da Fala: A Linguagem e os Seus Sons. 4th edn. Ática, São Paulo, SP, Brazil, 52-70.

28. Roodenrys S, Hulme C \& Brown G (1993). The development of short-term memory span: Separable effects of speech rate and longterm memory. Journal of Experimental Child Psychology, 56: 431442.

Appendix 1. Examples of phoneme and order error in the Brazilian Children's Test of Pseudoword Repetition.

\begin{tabular}{|c|c|c|c|}
\hline Target & Phonetic transcription & Phonotactic structure & Error category \\
\hline Jama & Zama & crev & j-a-m-a (S-1-1-1) \\
\hline Mantura & Mantua & cve-crev & m-a-n-t-u-r-a (1-1-1-1-1-0-1) \\
\hline Ampisco & Rampisco & vc-cvc-cv & a-m-p-i-s-c-o (A-1-1-1-1-1-1) \\
\hline Belinidade & Benilidade & crevevevev & b-e-n-i-l-i-d-a-d-e (1-1-M-1-M-1-1-1-1) \\
\hline
\end{tabular}

$\mathrm{c}=$ consonant; $\mathrm{v}=$ vowel; 1 = correct phoneme; $\mathrm{S}=$ substitution; $\mathrm{O}=$ omission; $\mathrm{A}=$ addition; $\mathrm{M}=$ migration.

Appendix 2. BCPR stimuli with "consonant-vowel" phonotactic structure.

\begin{tabular}{|llll|}
\hline Jama & Volinho & Panininha & Belinidade \\
Pibo & Talugo & Cocarelo & Naripadura \\
Vana & Barita & Muralito & Cabajucaba \\
Muca & Begina & Limarado & Melanitito \\
Lajo & Porate & Micharrinho & \\
Riga & Magalo & & \\
\hline
\end{tabular}

Twenty-two nonwords selected for sets 2 and 3 of statistical analysis. 